\title{
Incidence and maternal-fetal risk factors of stillbirth: A population-based historical cohort and a nested case-control study
}

\section{Zahra Maleki}

Shiraz University of Medical Sciences

Haleh Ghaem ( $\nabla$ hale.ghaem.sums@gmail.com )

Shiraz University of Medical Sciences

\section{Mozhgan Seif}

Shiraz University of Medical Sciences

\section{Sedigheh Foruhari}

Shiraz University of Medical Sciences

Research article

Keywords: Pregnancy, Cohort, Fetal death, Stillbirth, Risk factors

Posted Date: December 9th, 2019

DOI: https://doi.org/10.21203/rs.2.18523/v1

License: (c) (i) This work is licensed under a Creative Commons Attribution 4.0 International License. Read Full License 


\section{Abstract}

Background: For parents, stillbirth is a disappointing phenomenon; thus, identifying the associated risk factors can be beneficial in order to prevent this event. This study aimed to investigate the incidence and risk factors associated with stillbirth.

Methods: In this historical cohort study, a total of 18129 birth records were investigated. For each case of stillbirth, three live birth infants on the same day and same hospital were selected as the controls, which were matched for gestational age. The data was collected using a researcher-made checklist. Finally, data were analyzed using STATA, 13.0 with Cox proportional hazards regression model at the significance level of 0.05 .

Results: The cumulative incidence of still birth was 9.48 per 1000 live births. Based on multivariate Cox regression model, five risk factors for stillbirth were identified, including male gender, fetal diseases, gestational hypertension, gestational diabetes, and hypothyroidism, (all hazard ratios $>1$ and $p<0.05$ ).

Conclusion: For the first time, maternal hypothyroidism, oligohydramnios and polyhydramnios were shown as risk factors for stillbirth, which were not evaluated in any previous study. The findings of this study suggest that some maternal and fetal risk factors can be recognized as predictors of stillbirth, which might help to prevent and detect high-risk parents at early stages in order to avoid adverse health consequences in the mother and her neonate.

\section{Background}

According to world health organization (WHO), stillbirth is defined as the number of babies born without signs of life at or greater than 28 completed weeks' gestation with weight $<1000$ gr or height $<35 \mathrm{~cm}$ [1]. Despite the increasing attention toward maternal, neonatal and child health, stillbirths still remain a major public health concern, as not counted in the millennium development goals, nor current sustainable development goals [2]. In recent years, attempts were made, using documented data to establish standard cut-offs for pregnancy and birth weight [3]. In 2015, WHO estimated that 2.6 million stillbirths, ranging from 3.0-0.4 million occurs annually throughout the world [4]. About 98 percent of stillbirths occur in low- and middle-income countries, especially in sub-Saharan Africa and South Asia [5-7]. Stillbirth rate is 10 times higher in the developing countries than in the developed ones $[3,8]$. Almost 47,000 stillbirth occurs yearly in Tanzania [7]. Generally, the rate of stillbirth in developing countries is estimated at 25.5 per 1000 births, whereas it is 5.3 per 1000 births in developed countries [3]. There are many maternal and fetal risk factors for stillbirth, including smoking, alcohol consumption, number of delivery $\geq 3$, high maternal age (over 35 years), low maternal education, chronic maternal diseases, preeclampsia, multiparty, gestational diabetes, antepartum hemorrhage, premature rupture of membranes, hypertensive conditions in pregnancy, caesarean section, cephalo-pelvic disproportion, prolonged / obstructed labor, and congenital abnormalities, lack of antenatal care, poor maternal nutrition, infections during pregnancy, birth asphyxia, and intra- uterine growth restriction [9-16]. 
Since still birth might cause severe psychological problems such as stress, anxiety and depression for the involved mother and her family, this issue can lead to irreparable mental damage and high burden of costs to the family and healthcare system, affecting future pregnancies [17].

To date, no study has investigated risk factors for stillbirths, using statistical modeling through a population-based study, and most of the studies using small sample size have examined merely the incidence of stillbirths. Although, a few studies in other countries have identified the risk factors associated with stillbirth, maternal and fetal variables were not simultaneously evaluated. Therefore, this is the first study with a large sample size determining the incidence of stillbirths through a populationbased cohort study, by identifying risk factors for stillbirth according to two maternal and fetal causes.

\section{Methods}

\section{Study procedure}

This study design was conducted in two historical cohort and nested case-control phases.

\section{Phase 1: Historical cohort}

This study reviewed a total of 18129 medical records in five major midwifery hospitals (three tertiary and two private hospitals) in Shiraz, the capital of Fars province, Iran, using census method between March 2016 and March 2017. The cohort included all cases of pregnant women who referred to these hospitals for termination of their pregnancy, including vaginal delivery, cesarean section, and stillbirth. It should be mentioned that all standard forms of the Ministry of Health were added to the patients' medical records, and were completed by midwives and operating room nurses.

\section{Phase 2: Nested case-control cohort}

For each case of stillbirth, three controls were selected from those who had not experienced stillbirth, and had given live births in the same hospital on the same day. In both case and control groups, week of gestation was acknowledged as a time-matched variable, and the required data were obtained using a researcher-made checklist.

Study variables were maternal characteristics, such as age, blood group, blood $\mathrm{RH}$, number of labors, number of abortion, mode of delivery, maternal disease during pregnancy (at least having one of following diseases: gestational diabetes mellitus, gestational hypertension (blood pressure $\geq 140 / 90$ $\mathrm{mm} \mathrm{Hg}$ ) and hypothyroidism); and fetal characteristics, including fetus gender, birth weight, fetal disease (at least having one of following diseases: Intrauterine growth restriction (IUGR), congenital anomaly, chromosomal disorder, oligohydramnios, polyhydramnios, brain disorder and severe hydrops). All female residents of Shiraz with Iranian nationality referred to the obstetrics units of the selected hospitals were eligible for recruitment in this study. This study used a time-to-event method for weeks of gestation in both case and control cohorts, and Cox regression model was implemented to investigate factors associated with stillbirth. Positive Hazard Ratio (HR) means that it causes the variable increases the 
event of stillbirth. For modelling, the variables with $p<0.2$ were entered into the multivariate Cox regression model. All study variables were analyzed using STATA software, version13.0. Descriptive data are presented as mean and Standard Deviation ( \pm SD) for continuous variables and frequency (\%) for categorical ones. The differences between subgroups were compared using independent-sample t-test and Chi-square test. All quantitative variables were tested for normal distribution by Kolmogorov-Smirnov test and statistical graphs (i.e. histogram and box-plot). Univariate and multivariate Cox regression analyses were applied and reported separately for both maternal and fetal variables. (Verbal consent was obtained from each patient when admitted to the hospital by medical staff.)

\section{Results}

\section{Maternal risk factors}

The average age for mothers was $28.72 \pm 5.99$ years, ranging $16-45$ years. Table 1 shows demographic and clinical characteristics of the participants.

In our study, the cumulative incidence of stillbirth was 9.48 per 1000 live births (95\% Confidence Interval (Cl) 8-11). The incidence of stillbirth was 0.38 (95\% Cl 0.1-0.7), 7.72 (95\% Cl 6-9) and 1.37 (95\% Cl 0.8-2) per 1000 live births amongst mothers under the age of 20,20 to 35 , and 35 and older age, respectively.

Among maternal variables, maternal age, number of abortions, number of deliveries, blood group, blood $\mathrm{RH}$, maternal diseases (e.g. gestational hypertension, gestational diabetes mellitus, and hypothyroidism) were associated with stillbirth in maternal Univariate analysis [Table 2]. Eventually, in modelling using multivariate cox regression analysis, three maternal variables remained as the most important predictors of stillbirth, including pregnancy hypertension $(\mathrm{HR}=2.38 ; 95 \% \mathrm{Cl} 1.38-4.12 ; \mathrm{p}$-value $=0.002)$, hypothyroidism $(\mathrm{HR}=2.24 ; 95 \% \mathrm{Cl} 1.37-3.63 ; \mathrm{p}$-value=0.001), and gestational diabetes mellitus $(\mathrm{HR}=1.94 ; 95 \% \mathrm{Cl} 1.17-3.24$; $\mathrm{p}$-value $=0.010)$ [Table 3and Figure 1].

\section{Fetal risk factors}

The incidence of stillbirth amongst males and females were 8.32 (95\% Cl 7-9) and 1.15 (95\% Cl 0.7-1) per 1000 live births, respectively. Among fetal variables, male gender, birth weight and fetal diseases (i.e. IUGR, congenital anomaly, chromosomal disorder, oligohydramnios, polyhydramnios, brain disorder and severe hydrops) were associated with stillbirth in maternal Univariate analysis [Table 2]. Finally, results of statistical modelling with multivariate cox regression showed that two fetal variables remained as the most important predictors of stillbirth, including male gender(HR=3.45;95\% $\mathrm{Cl} 2.16-5.50 ; p$-value $=0.001)$ and fetal diseases (IUGR, congenital anomaly, chromosomal disorder, oligohydramnios, polyhydramnios, brain disorder and severe hydrops) $(\mathrm{HR}=3.23 ; 95 \% \mathrm{Cl} 2.30-4.54$; $\mathrm{p}$-value $=0.001)$ [Table 3and Figure 1].

\section{Discussion}


In this historical cohort study conducted among 18129 hospital records, the following results were reached: the cumulative incidence rate of stillbirth was 9.48 per 1000 live birth. Among maternal causes, gestational hypertension was identified as the first risk factor associated with increased risk of stillbirth. The findings also showed that gestational diabetes was the other risk factor for stillbirth, which increased the risk by twofold. Pregnant women with hypothyroidism were twice more likely to have stillbirth than healthy pregnant women. Amongst fetal causes, male gender increased the risk of still birth by more than threefold. Fetal disease (i.e. IUGR, congenital anomaly, chromosomal disorder, oligohydramnios, polyhydramnios, brain disorder and severe hydrops) was identified as the other main predictor of stillbirth, which increased the risk by threefold. For the first time, maternal hypothyroidism, oligohydramnios and polyhydramnios were shown as risk factors for stillbirth, which were not evaluated in any previous study.

\section{Maternal predictors}

The findings of this study showed that the cumulative incidence of stillbirth was 9.48 per 1000 live birth. In a study conducted by Tshibumbu et al., 2014 in Namibia, the rate of stillbirth was reported as 12 per 1000 births [18], and the incidence of the stillbirth in hospital in few months was $8 \%$ or 80 per 1000 births [19]. However, Blencowe et al., 2016 estimated the rate of stillbirth as 23 per 1000 live births in India [20]. Our estimates of stillbirth incidence was much lower, which can be due to racial, environmental, and socioeconomic differences or variations in data collection methods.

In addition, Neogi et al., 2018, Newtonraj et al.,2017, Ashish et al.,2015, Liu et al.,2014, Al-kadri et al.,2012, Mutihir et al.,2010, concluded that gestational hypertension was one of the factors associated with stillbirth, which was in line with the results of our study [21-26]. Gestational hypertension increases the risk placenta to be separated earlier by twofold, leading to fetal-growth disorders, by increasing the risk of maternal mortality by threefold [27].

Furthermore, gestational diabetes mellitus was shown to be significantly associated with stillbirth, which is consistent with the systematic review of Liu et al., 2014, indicating that gestational diabetes mellitus increased the risk of stillbirth by 2 to 5 folds. This was also supported by the results of Kean et al., 2009, Casson IF et al.,1997, Dunne F et al., 2003, Dunne FP et al., 2009, [26,28-31]. Birth weight greater than $4000 \mathrm{~g}$ is shown to increase the rate of stillbirth in diabetic mothers [32]. There is evidence that fetus of diabetic mothers classified as large for gestational age, is at greater risk of stillbirth [33]. Even with a strong efficient patient monitoring system, women with gestational diabetes mellitus are still at high risk for stillbirth [34]. In fact, certain increase in blood glucose level or a sudden onset of diabetes mellitus in the third trimester of pregnancy might lead to fetal death [35].

In addition, it was concluded that hypothyroidism could lead to stillbirth, which was consistent with the results of Liu et al., 2014, and other previous studies [26,36-38]. This is justifiable, since endocrine disorders (thyroid dysfunction) occurs mainly in women, and its prevalence amongst women in Shiraz, is high [39]. Azizi et al., concluded that maternal hypothyroidism during pregnancy leads to placenta abruption, prematurity and low birth weight, intrauterine growth restriction, congenital malformations and 
stillbirth [40]. In addition, thyroid disease is very common in Iran, especially among women, and many women of childbearing age who have hypothyroidism are unaware of their illness [41]. Chen et al., 2014 proposed that hypothyroidism leads to IUGR, hypertension and premature rupture of membranes [42].

\section{Fetal predictors}

Rate of stillbirth amongst male gender is 3 times higher than females, which is supported by Mutihir et al., 2010, and male gender is two times more likely to have stillbirth [23]. This can be due to higher susceptibility of the male gender in the embryonic period, as well as higher rate of male birth [43-48].

Novelty, according to the findings of this study, fetal diseases (IUGR, congenital anomaly, chromosomal disorder, oligohydramnios, polyhydramnios, brain disorder and severe hydrops) were associated with increased risk of stillbirth by threefold, which was consistent with results of Patel et al., 2014, Newtonraj et al., 2017, Kean et al., 2009, and Liu et al., 2013 [28,36,40,49]. It should be noted that for the first time, maternal hypothyroidism, oligohydramnios and polyhydramnios were shown as risk factors for stillbirth, which were not evaluated in any previous study.

Importantly, in the present study, Univariate analysis without considering the confounding effect of some covariates such as maternal age, mother's blood group, number of abortion and fetal weight were shown to be associated with still birth. However, after taking into account the confounding effect, these variables did not remain as risk factor. Therefore, interpretation of the result without considering the confounding effect would be misleading.

\section{Conclusion}

For the first time in Iran, the cumulative incidence rate of stillbirth was revealed to be 9.48 per 1000 live births in this population-based historical cohort study.

This study indicate that the predictors of stillbirth include fetus gender, gestational hypertension, gestational hypothyroidism, gestational diabetes mellitus and fetal diseases (IUGR, congenital anomaly, chromosomal disorder, oligohydramnios, polyhydramnios, brain disorder and severe hydrops). Importantly, the findings of our study suggest that maternal hypothyroidism, oligohydramnios and polyhydramnios were risk factors for stillbirth, which were not evaluated in any previous study. Also, our study confirmed that without considering the confounding effect through statistical modelling, the interpretation of the result would be ambiguous.

\section{Declarations}

\section{Acknowledgments}

This article was extracted from Zahra Maleki's M.Sc. thesis approved and The authors would also express their gratitude to all staff of medical records department of Shiraz obstetrics and gynecology 
hospitals for their cooperation. The authors wish to thank Mr. H. Argasi at the Research Consultation Center (RCC) of Shiraz University of Medical Sciences for his invaluable assistance in editing this manuscript.

\section{Funding}

financially supported by the Research Vice-chancellor of Shiraz University of Medical Sciences Grant No:97-01-04-18095, Ethical code: IR.SUMS.REC.1397.912 ).

\section{Contributions}

Zahra Maleki gathering data, analysis and retained. Haleh Ghaem developed the idea and contributed to data analysis and critically reviewed the manuscript. Mozhgan Seif contributed to data analysis and critically reviewed the manuscript. Sedigheh Fourohari helped to developing the questionnaire and critically reviewed the manuscript. All authors contributed to review of the manuscript and approved the final draft.

\section{Corresponding author}

Correspondence to Haleh Ghaem

\section{Ethics declarations}

\section{Ethics approval and consent to participate}

Ethical approvals were obtained from the Shiraz University of medical sciences, the Shiraz Medical Research Institute Ethical Review Committee.

\section{Consent for publication}

Not applicable.

\section{Competing interests}

The authors declare that they have no competing interests.

Author contributions: Zahra Maleki gathering data, analysis and retained. Haleh Ghaem developed the idea and contributed to data analysis and critically reviewed the manuscript. Mozhgan Seif contributed to data analysis and critically reviewed the manuscript. Sedigheh Forouhari helped to developing the questionnaire and critically reviewed the manuscript. All authors of this paper have read and approved the final version submitted.

\section{Availability of data and materials}


The datasets used and/or analyzed during the current study are available from the corresponding author on reasonable request.

\section{Abbreviations}

WHO: world health organization

IU: Intrauterine growth restriction

HR: Hazard Ratio

SD: Standard Deviation

Cl: confidence interval

\section{References}

1. Organization WH (2016) Making every baby count: audit and review of stillbirths and neonatal deaths.

2. Okeudo C, Ezem B, Ojiyi E (2012) Stillbirth Rate in a Teaching Hospital in South. Eastern Nigeria: A Silent Tragedy. Annals of medical and health sciences research 2 (2):176-179

3. Stanton C, Lawn JE, Rahman H, Wilczynska-Ketende K, Hill K (2006) Stillbirth rates: delivering estimates in 190 countries. The Lancet 367 (9521):1487-1494

4. Organization WH (2014) WHO recommendations on postnatal care of the mother and newborn. World Health Organization,

5. Chuwa FS, Mwanamsangu AH, Brown BG, Msuya SE, Senkoro EE, Mnali OP, Mazuguni F, Mahande MJ (2017) Maternal and fetal risk factors for stillbirth in northern Tanzania: a registry-based retrospective cohort study. PloS one 12 (8):e0182250

6. McClure EM, Wright LL, Goldenberg RL, Goudar SS, Parida SN, Jehan I, Tshefu A, Chomba E, Althabe F, Garces A (2007) The global network: a prospective study of stillbirths in developing countries. American journal of obstetrics and gynecology 197 (3):247. e241-247. e245

7. McClure EM, Pasha O, Goudar SS, Chomba E, Garces A, Tshefu A, Althabe F, Esamai F, Patel A, Wright LL (2011) Epidemiology of stillbirth in low-middle income countries: A Global Network Study. Acta obstetricia et gynecologica Scandinavica 90 (12):1379-1385

8. McClure E, Wright L, Goldenberg R, Goudar S, Mohapatra A, Jehan I, Tshefu A, Chomba E, Garces A, Althabe $F$ (2006) A prospective study of stillbirths in developing countries. American Journal of Obstetrics \& Gynecology 195 (6):S220

9. Tolefac PN, Tamambang RF, Yeika E, Mbwagbaw LT, Egbe TO (2017) Ten years analysis of stillbirth in a tertiary hospital in sub-Sahara Africa: a case control study. BMC research notes 10 (1):447 
10. Alfirevic Z, Neilson JP (1996) Biophysical profile for fetal assessment in high risk pregnancies. Cochrane database of systematic reviews (1)

11. Gordon A, Raynes-Greenow C, McGeechan K, Morris J, Jeffery H (2013) Risk factors for antepartum stillbirth and the influence of maternal age in New South Wales Australia: a population based study. BMC pregnancy and childbirth 13 (1):12

12. Getahun D, Ananth CV, Kinzler WL (2007) Risk factors for antepartum and intrapartum stillbirth: a population-based study. American journal of obstetrics and gynecology 196 (6):499-507

13. Salihu HM, Wilson RE, Alio AP, Kirby RS (2008) Advanced maternal age and risk of antepartum and intrapartum stillbirth. Journal of Obstetrics and Gynaecology Research 34 (5):843-850

14. Facchinetti F, Alberico S, Benedetto C, Cetin I, Cozzolino S, Di Renzo GC, Del Giovane C, Ferrari F, Mecacci F, Menato G (2011) A multicenter, case-control study on risk factors for antepartum stillbirth. The journal of maternal-fetal \& neonatal medicine 24 (3):407-410

15. Guevvera Y (2006) World Health Organisation: Neonatal and perinatal mortality: country, regional and global estimates. WHO. cebu: sun,

16. Avachat SS, Phalke DB, Phalke VD (2015) Risk factors associated with stillbirths in the rural area of Western Maharashtra, India. Archives of Medicine and Health Sciences 3 (1):56

17. Frøen JF, Cacciatore J, McClure EM, Kuti O, Jokhio AH, Islam M, Shiffman J, Committee LsSSS (2011) Stillbirths: why they matter. The Lancet 377 (9774):1353-1366

18. Tshibumbu DD, Blitz J (2016) Modifiable antenatal risk factors for stillbirth amongst pregnant women in the Omusati region, Namibia. African journal of primary health care \& family medicine 8 (1):1-6

19. Tilahun D, Assefa T (2017) Incidence and determinants of stillbirth among women who gave birth in Jimma University specialized hospital, Ethiopia. Pan African Medical Journal 28 (1)

20. Blencowe H, Cousens S, Jassir FB, Say L, Chou D, Mathers C, Hogan D, Shiekh S, Qureshi ZU, You D (2016) National, regional, and worldwide estimates of stillbirth rates in 2015, with trends from 2000: a systematic analysis. The Lancet Global Health 4 (2):e98-e108

21. Al-Kadri HM, Tamim HM (2012) Factors contributing to intra-uterine fetal death. Archives of gynecology and obstetrics 286 (5):1109-1116

22. Ashish K, Wrammert J, Ewald U, Clark RB, Gautam J, Baral G, Baral KP, Målqvist M (2016) Incidence of intrapartum stillbirth and associated risk factors in tertiary care setting of Nepal: a case-control study. Reproductive health 13 (1):103

23. Mutihir J, Eka P (2011) Stillbirths at the Jos University Teaching Hospital: incidence, risk, and etiological factors. Nigerian journal of clinical practice 14 (1)

24. Newtonraj A, Kaur M, Gupta M, Kumar R (2017) Level, causes, and risk factors of stillbirth: a population-based case control study from Chandigarh, India. BMC pregnancy and childbirth 17 (1):371 
25. Neogi SB, Sharma J, Negandhi P, Chauhan M, Reddy S, Sethy G (2018) Risk factors for stillbirths: how much can a responsive health system prevent? BMC pregnancy and childbirth 18 (1):33

26. Liu L-C, Wang Y-C, Yu M-H, Su H-Y (2014) Major risk factors for stillbirth in different trimesters of pregnancy-a systematic review. Taiwanese Journal of Obstetrics and Gynecology 53 (2):141-145

27. Fretts RC (2001) Maternal age and fetal loss. Older women have increased risk of unexplained fetal deaths. BMJ (Clinical research ed) 322 (7283):430

28. Siddiqui F, Kean L (2009) Intrauterine fetal death. Obstetrics, Gynaecology \& Reproductive Medicine $19(1): 1-6$

29. Casson I, Clarke C, Howard C, McKendrick O, Pennycook S, Pharoah P, Platt M, Stanisstreet M, Van Velszen D, Walkinshaw S (1997) Outcomes of pregnancy in insulin dependent diabetic women: results of a five year population cohort study. Bmj 315 (7103):275-278

30. Dunne F, Brydon P, Smith K, Gee H (2003) Pregnancy in women with type 2 diabetes: 12 years outcome data 1990-2002. Diabetic Medicine 20 (9):734-738

31. Dunne FP, Avalos G, Durkan M, Mitchell Y, Gallacher T, Keenan M, Hogan M, Carmody LA, Gaffney G, collaborators AD (2009) ATLANTIC DIP: pregnancy outcome for women with pregestational diabetes along the Irish Atlantic seaboard. Diabetes Care 32 (7):1205-1206

32. Mondestin MA, Ananth CV, Smulian JC, Vintzileos AM (2002) Birth weight and fetal death in the United States: the effect of maternal diabetes during pregnancy. American journal of obstetrics and gynecology 187 (4):922-926

33. Günter $H$, Tzialidou I, Scharf $A$, Wenzlaff $P$, Maul H, Hillemanns $P$ (2006) Intrauterine fetal death in pregnancies of women with preconceptional and gestational diabetes mellitus and of women without glucose tolerance disorders. Results of the perinatal registry of Lower Saxony, Germany. Zeitschrift fur Geburtshilfe und Neonatologie 210 (6):193-199

34. Girz B, Divon M, Merkatz IR (1992) Sudden fetal death in women with well-controlled, intensively monitored gestational diabetes. Journal of perinatology: official journal of the California Perinatal Association 12 (3):229-233

35. Bresson L, Bourgain A, Depret T, Vambergue A, Dubos J, Deruelle P, Houfflin-Debarge V (2010) Ketoacidosis complicated by fetal death revealing fulminant diabetes during the third trimester of pregnancy. Journal de gynecologie, obstetrique et biologie de la reproduction 39 (7):588-591

36. Liu L-C, Huang H-B, Yu M-H, Su H-Y (2013) Analysis of intrauterine fetal demise-A hospital-based study in Taiwan over a decade. Taiwanese Journal of Obstetrics and Gynecology 52 (4):546-550

37. Sahu MT, Das V, Mittal S, Agarwal A, Sahu M (2010) Overt and subclinical thyroid dysfunction among Indian pregnant women and its effect on maternal and fetal outcome. Archives of gynecology and obstetrics 281 (2):215

38. Casey BM, Dashe JS, Wells CE, McIntire DD, Byrd W, Leveno KJ, Cunningham FG (2005) Subclinical hypothyroidism and pregnancy outcomes. Obstetrics \& Gynecology 105 (2):239-245

39. Fariba Karimi M, Ranjbar G, Omrani M (2014) Thyroid disorders and the prevalence of antithyroid antibodies in Shiraz population. Archives of Iranian medicine 17 (5):347 
40. Leung AS, Millar LK, Koonings PP, Montoro M, Mestman JH (1993) Perinatal outcome in hypothyroid pregnancies. Obstetrics and gynecology 81 (3):349-353

41. Bülbül M, Çetinkaya S, Ekşioğlu S, Özkasap S, Giniş T (2009) Kidney growth in children with congenital hypothyroidism. Pediatric Nephrology 24 (2):333

42. Chen L-M, Du W-J, Dai J, Zhang Q, Si G-X, Yang H, Ye E-L, Chen Q-S, Yu L-C, Zhang C (2014) Effects of subclinical hypothyroidism on maternal and perinatal outcomes during pregnancy: a single-center cohort study of a Chinese population. PloS one 9 (10):e109364

43. Berhan Y, Berhan A (2014) Meta-analysis of selected maternal and fetal factors for perinatal mortality. Ethiopian journal of health sciences 24:55-68

44. Olatinwo A, Anate M, Alao O (2000) Determinants of perinatal mortality among breech depvery in a Nigerian teaching hospital. Sahel Medical Journal 3 (1):26

45. Matendo R, Engmann C, Ditekemena J, Gado J, Tshefu A, Kinoshita R, McClure EM, Moore J, Wallace D, Carlo WA (2011) Reduced perinatal mortality following enhanced training of birth attendants in the Democratic Republic of Congo: a time-dependent effect. BMC medicine 9 (1):93

46. Carlo WA, Goudar SS, Jehan I, Chomba E, Tshefu A, Garces A, Sailajanandan P, Althabe F, McClure EM, Derman RJ (2010) Newborn-care training and perinatal mortality in developing countries. New England Journal of Medicine 362 (7):614-623

47. Oti S, Odimegwu C (2011) Perinatal mortality in Nigeria: do place of delivery and delivery assistants matter. Open Demography J 4:1-10

48. Andargie G, Berhane Y, Worku A, Kebede Y (2013) Predictors of perinatal mortality in rural population of Northwest Ethiopia: a prospective longitudinal study. BMC public health 13 (1):168

49. Patel S, Thaker R, Shah P, Majumder S (2014) Study of causes and complications of intra uterine fetal death (IUFD). Int J Reprod Contracept Obstet Gynecol 3 (4):931-935

\section{Tables}

Table 1. Maternal and fetal demographic/clinical characteristics 


\begin{tabular}{|c|c|c|c|}
\hline characteristics & $\begin{array}{c}\text { Case }(\mathrm{n}=172) \\
\mathrm{n}(\%)\end{array}$ & $\begin{array}{c}\text { Control }(\mathrm{n}=516) \\
\mathrm{n}(\%)\end{array}$ & P_value \\
\hline $\begin{array}{l}\text { Maternal age(year) } \\
20> \\
20-35 \\
35<\end{array}$ & $\begin{array}{c}7(4.1) \\
140(81.4) \\
25(14.5)\end{array}$ & $\begin{array}{c}45(8.7) \\
411(79.7) \\
60(11.6)\end{array}$ & 0.09 \\
\hline $\begin{array}{l}\text { Gestational hypertension } \\
\text { No } \\
\text { yes }\end{array}$ & $\begin{array}{l}152(88.4) \\
20(11.6)\end{array}$ & $\begin{array}{c}516(100) \\
0(0)\end{array}$ & $0.001>$ \\
\hline $\begin{array}{l}\text { Gestational hypothyroidism } \\
\text { No } \\
\text { yes }\end{array}$ & $\begin{array}{l}147(85.5) \\
25(14.5)\end{array}$ & $\begin{array}{c}515(99.8) \\
1(0.2)\end{array}$ & $0.001>$ \\
\hline $\begin{array}{l}\text { Gestational Diabetes mellitus } \\
\text { No } \\
\text { yes }\end{array}$ & $\begin{array}{l}145(84.3) \\
27(15.7)\end{array}$ & $\begin{array}{c}516(100) \\
0(0)\end{array}$ & $0.001>$ \\
\hline $\begin{array}{l}\text { Mod of delivery } \\
\text { Cesarean } \\
\text { Vaginal }\end{array}$ & $\begin{array}{c}5(3) \\
167(97)\end{array}$ & $\begin{array}{l}248(48) \\
268(52)\end{array}$ & $<0.001$ \\
\hline $\begin{array}{l}\text { Fetus gender } \\
\text { Female } \\
\text { Male }\end{array}$ & $\begin{array}{l}21(12.2) \\
151(87.8)\end{array}$ & $\begin{array}{l}240(46.5) \\
276(53.5)\end{array}$ & $0.001>$ \\
\hline $\begin{array}{l}\text { Fetal diseases } \\
\text { No } \\
\text { yes }\end{array}$ & $\begin{array}{l}102(59.3) \\
70(40.7)\end{array}$ & $\begin{array}{c}516(100) \\
0(0)\end{array}$ & $0.001>$ \\
\hline $\begin{array}{l}\text { Birth weight }(\mathrm{g}) \\
\text { mean } \pm \text { standard deviation }\end{array}$ & $388.09 \pm 428.98$ & $3036.61 \pm 331.30$ & $0.001>$ \\
\hline
\end{tabular}

Table 2. Univariate analysis on the relationship between the study factors and stillbirth 


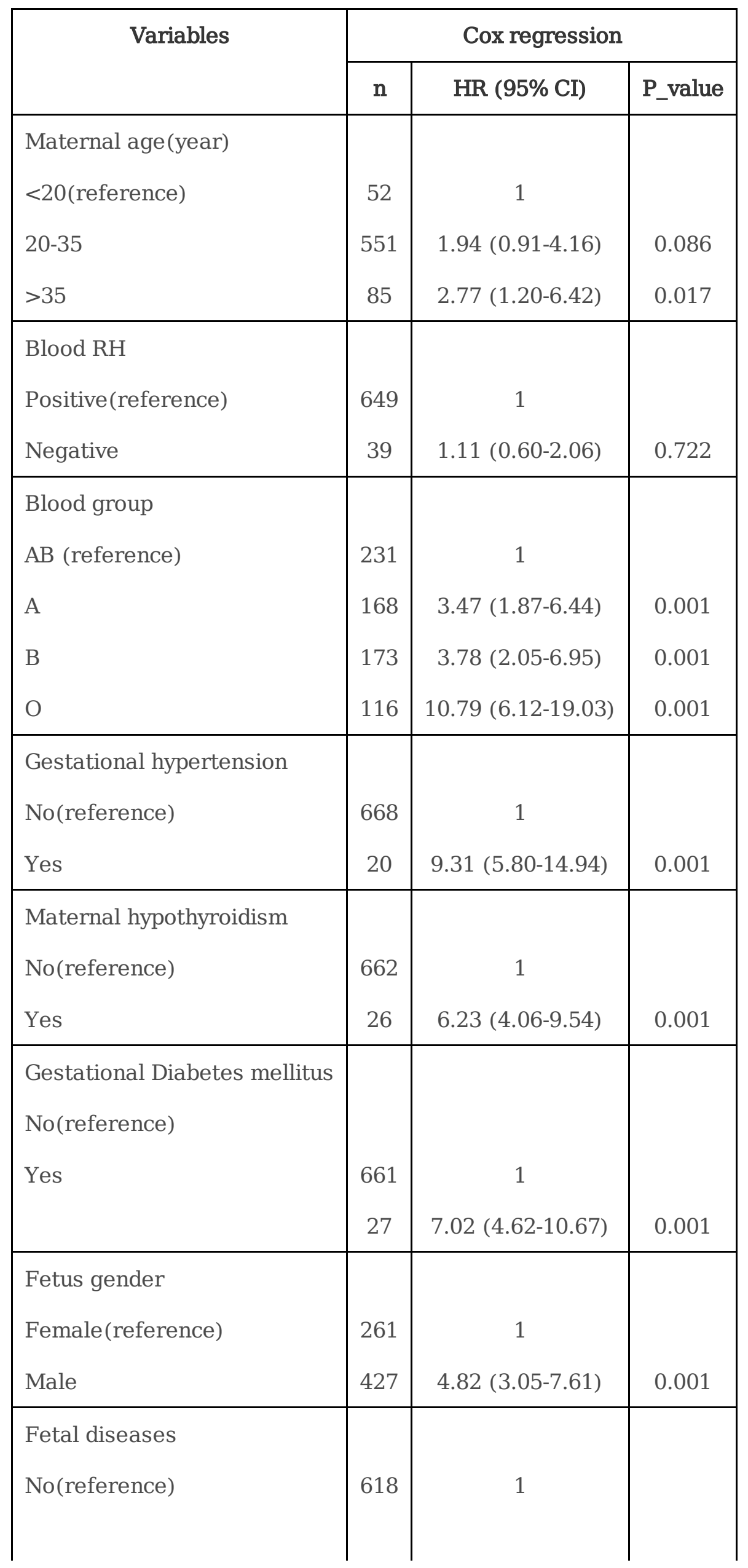




\begin{tabular}{|l|c|c|c|} 
Yes & 70 & $5.35(3.94-7.27)$ & 0.001 \\
\hline Fetal weight (gr) & 688 & $0.99(0.99-0.99)$ & 0.001 \\
\hline Number of abortions & 688 & $1.49(1.22-1.81)$ & 0.001 \\
\hline Number of labors & 688 & $1.10(0.94-1.29)$ & 0.200 \\
\hline
\end{tabular}

Table 3.Statistical modelling on the relationship between the study factors and stillbirth using multiple Cox regression

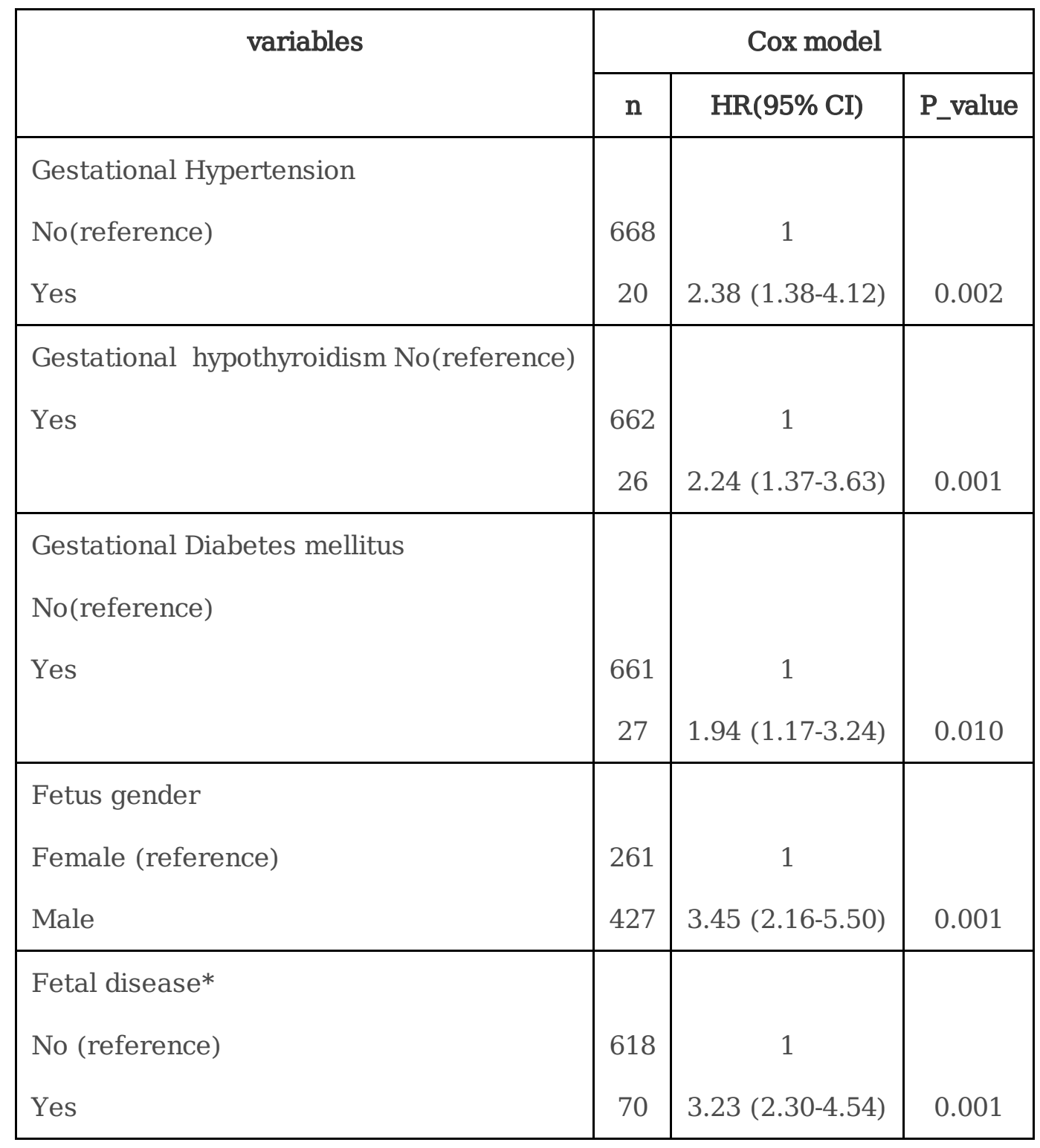

${ }^{*}$ Fetal disease (i.e. IUGR, congenital anomaly, chromosomal disorder, oligohydramnios, polyhydramnios, brain disorder and severe hydrops)

\section{Figures}




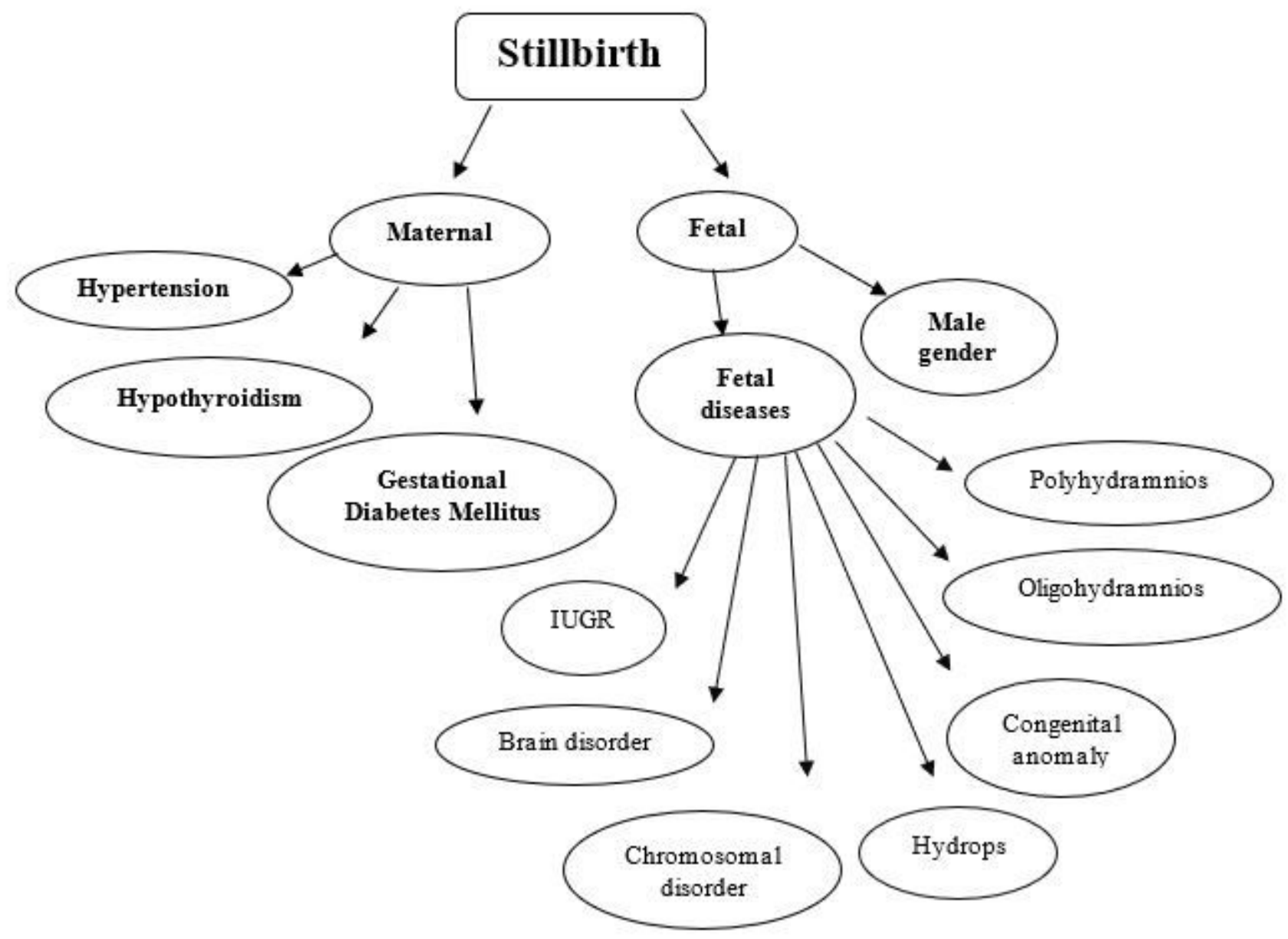

Figure 1

The maternal and fetal risk factors of stillbirth based on final modelling. 